\title{
UV ABSORPTION SPECTRA, IODOMETRIC DETERMINATION AND PH VARIATION IN OZONATED WATER USING OZONE GENERATOR
}

\author{
Mirela-Nicoleta Dinca, Mariana Ferdes, Bianca-Stefania Zabava, Irina-Aura Istrate \\ University Politehnica of Bucharest, Romania \\ mirela_dilea@yahoo.com,marianaferdes@yahoo.com, bianca.dragoiu@yahoo.com, \\ ia_istrate@yahoo.com
}

\begin{abstract}
An UV absorption spectroscopy technique for real time detecting of reactive ozone and nitrogen oxides species in ozonated water was compared with the traditional iodometric method. The UV absorption spectra are important for understanding the composition of ozonated water. A commercially available ozone generator was used to obtain ozonated water by the bubbling method. A volume of $200 \mathrm{ml}$ of distilled water was treated with the gaseous mixture resulted from the ozone generator. The UV absorption spectra were recorded between $200-300 \mathrm{~nm}$ and the ozone concentration wasdetermined by the iodometric method. The results showed the presence of some characteristic peaks for nitrogen oxides and ozonespecies in the UV absorption spectra, the values of the absorbance increasing in time. It has been shown that, due to the high nitrogen content in the air passed through the corona discharge, nitrogen oxides are mainly produced and less ozone. This could explain also the strong decrease of the $\mathrm{pH}$ values, after one hour of water ozonation. The iodometric analysis method showed the synthesis of some agents with strong oxidative potential, which can be both ozone and nitrogen oxides. The water sample treated for one hour with the ozone generator was analysed again after one week and one month, the results showing that reactive oxidizing species were kept also after this time. The UV absorption spectra, concentration of ozone $\left(\mathrm{g} \cdot \mathrm{l}^{-1}\right)$ determined by the traditional iodometric method and evolution of the $\mathrm{pH}$ values were assessed.
\end{abstract}

Keywords: ozone, corona discharge, ozonated water, iodometric method.

\section{Introduction}

Ozone is known to be a strong oxidant that can be used both in the potabilization of surface water and in wastewater treatment to remove microorganisms, inorganic ions and organic pollutants [1]. In addition, it quickly decomposes into oxygen molecules in water without forming any secondary contaminants [2]. Also, ozone is a powerful oxidant that has been accepted as a food sanitizer, mainly in organic farming, because it safely and spontaneously decomposes without forming hazardous residues [3]. When ozone comes in contact with organic compounds or bacteria, the extra atom of oxygen destroys the contaminant by oxidation [4]. Ozone is an unstable molecule, which rapidly decays into oxygen with a time constant that is dependent upon temperature and the presence of oxidable organic compounds. Because of this, ozone cannot be stored and must be generated at the point of use [5].For ozone generation, there are four recognized methods: corona discharge, ultraviolet radiation, electrolysis and radiochemical method. The use of electrical power to generate ozone by corona discharge is the most commercially viable method [6]. Ozone is formed by electric discharge through oxygen or air, but the generation of ozone in air is more complicated than that in pure oxygen due to the presence of nitrogen and water vapour. Experimental studies have considered the dependence of the ozone generation on the discharge polarity, current level, electrode size, temperature, air velocity and relative humidity [7;8].

Oh J.S. et al [9] investigated ozonated water using a conventional UV-Vis spectrophotometer. They compared the UV absorption spectra of ozone in water generated by $\mathrm{O}_{2}$ andby air plasma bubbling method. The authors reported that there were observed changes in the UV absorption spectra of ozonated waterin time. The ozonated water contained high concentration of $\mathrm{H}_{2} \mathrm{O}_{2}, \mathrm{O}_{2}$ and relatively low concentration of $\mathrm{O}_{3}$.In the present paper physico - chemical changes were evaluated produced in distilled water through gas bubbling generated by corona discharge using an ozone generator type OZONFIX 8G.

\section{Materials and methods}

\section{Ozone production}

Ozone was produced by a mobile ozone generator type OZONFIX $8 \mathrm{G}$, with the following characteristics: ozone production $8 \mathrm{~g} \cdot \mathrm{h}^{-1}$, power $16 \mathrm{~W}$, air cooling, gas flow (measured) $2.5 \mathrm{l} \cdot \mathrm{min}^{-1}$, used for air and water treatment. All the experiments were conducted at temperature of $20^{\circ} \mathrm{C}$. 


\section{Methods}

The gas resulted from the ozone generator with a flow rate of $2.51 \cdot \mathrm{min}^{-1}$ was bubbled in a volume of 11 distilled water in a $30 \mathrm{~cm}$ cylindrical vessel, through a ceramic frit with dimensions of $3 \times 1.8 \mathrm{~cm}$, for different times, between 30 seconds and 1 hour. At these time intervals, water samples with a volume of $5 \mathrm{ml}$ were collected. The $\mathrm{pH}$ was measured using a pH meter type InoLab Multilevel 1 and the UV absorption spectra were plotted between 200 and $300 \mathrm{~nm}$, using a T92 + UV- VIS spectrophotometer, PG Instruments with quartz cuvettes. All the samples were diluted 1:200 with distilled water in order to fit into the valid absorption range.

For determination of the formed ozone and oxidizing agents in the liquid medium, the traditional iodometric analysis method was used [10]. The gas produced by the ozone generator was bubbled through the ceramic frit into $200 \mathrm{ml}$ of $0.2 \mathrm{M} \mathrm{KI}$ solutionin a cylindrical vessel, thus the height of the liquid was $15 \mathrm{~cm}$. Generated ozone, as well as any other oxidizing agents, reacted with iodide to form iodine. Samples of $10 \mathrm{ml}$ were taken after 30 seconds to 20 minutes. The solution with formed iodine was poured into the titration vessel, it was acidified by $1 \mathrm{ml}$ of $2 \mathrm{M} \mathrm{HCl}$ and then it was nitrated by $0.05 \mathrm{M} \mathrm{Na}_{2} \mathrm{~S}_{2} \mathrm{O}_{3}$ solution until discolouring. To make this reaction more sensitive, a starch solution was added before the end of the titration. The amount of ozone was determined from the consumed solution of thiosulfate ( $1 \mathrm{ml}$ of $0.05 \mathrm{M} \mathrm{Na}_{2} \mathrm{~S}_{2} \mathrm{O}_{3}$ solution corresponds to $1.2 \mathrm{mg}$ ozone).

\section{Results and discussion}

The accumulation of ozone and possible oxidant agents in solution was monitored by the traditional iodometric method, depending on time. In Fig. 1 it can be noticed that the accumulation of ozone and, eventually, of nitrogen oxides (resulted from the oxidation of atmospheric nitrogen entered into the device) begins after the first 30 seconds. This aspect has been highlighted also by the fact that the $0.2 \mathrm{M}$ potassium iodide solution started to become light yellow after this period. The ozone and nitrogen oxides showed an increasing concentration over time, reaching up to an equivalent value of $1650 \mathrm{mg} \mathrm{O}{ }_{3} \cdot 1^{-1}$.After 20 minutes, the oxidation process was so strong that it determined the precipitation of $\mathrm{I}_{2}$ from the KI solution. This phenomenon is explained by the presence of oxidizing agents ozone-nitrogen oxide formed through the reactions (1) and (2) mentioned below. These equations are possible reactions of aqueous plasma generating reactive oxygen species with water and other oxygen species. In theory, plasma generates different reactive species: $\mathrm{O}_{2}$ can generate reactive oxygen species, while air can generate both reactive oxygen species and reactive nitrogen species [9].

$$
\begin{aligned}
& \mathrm{O}+\mathrm{H}_{2} \mathrm{O} \rightarrow \mathrm{H}_{2} \mathrm{O}_{2}, \\
& \mathrm{O}+\mathrm{O}_{2}(\mathrm{aq}) \rightarrow \mathrm{O}_{3} .
\end{aligned}
$$

The high concentration of oxidants is explained by the characteristics of the device and by the low volume of KI, in which the gas from the ozone generator was bubbled.

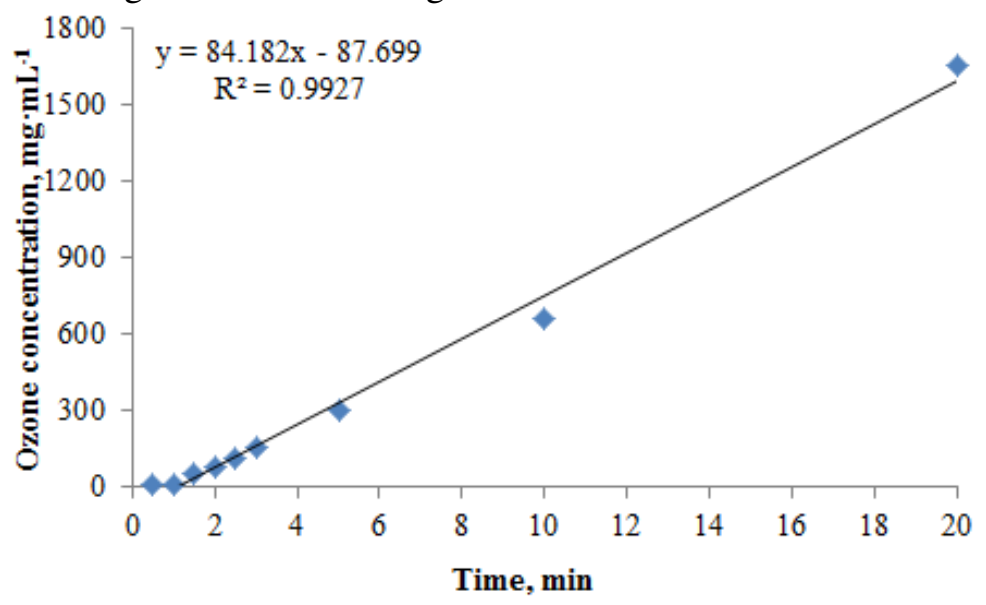

Fig. 1. Variation of ozone concentration in time

In parallel with this usual titrimetric method, the production of nitrogen oxides and ozone was observed by recording the absorption spectra in UV between 200 and $300 \mathrm{~nm}$. It is known that ozone has a maximum absorption at the wavelength of $260 \mathrm{~nm}$ and the nitrogen oxides at $205 \mathrm{~nm}$ [9]. 
Fig. 2 shows absorption spectra for the ozonated water samples taken between 30 seconds and 60 minutes. All the 13 graphs have been plotted on the same figure in order to compare the absorbance values. It can be observed that the absorbance values are increasing in time.

The absorbance values for 260 and $205 \mathrm{~nm}$ wavelengths were determined both in diluted samples (1:200) in the time interval between 30 seconds and 60 minutes (Fig. 3) during gas bubbling from the ozone generator and after the device was stopped at $30 \mathrm{~min}, 60 \mathrm{~min}, 3$ days, 7 days and one month. It was found that the absorbance recorded at $205 \mathrm{~nm}$ wavelengths (specific for nitrogen oxides) decreased from 1.267, the maximum value obtained after 60 minutes of bubbling, at 0.209 after one month. It was found that, even after one month, nitrogen oxides remained in the water.

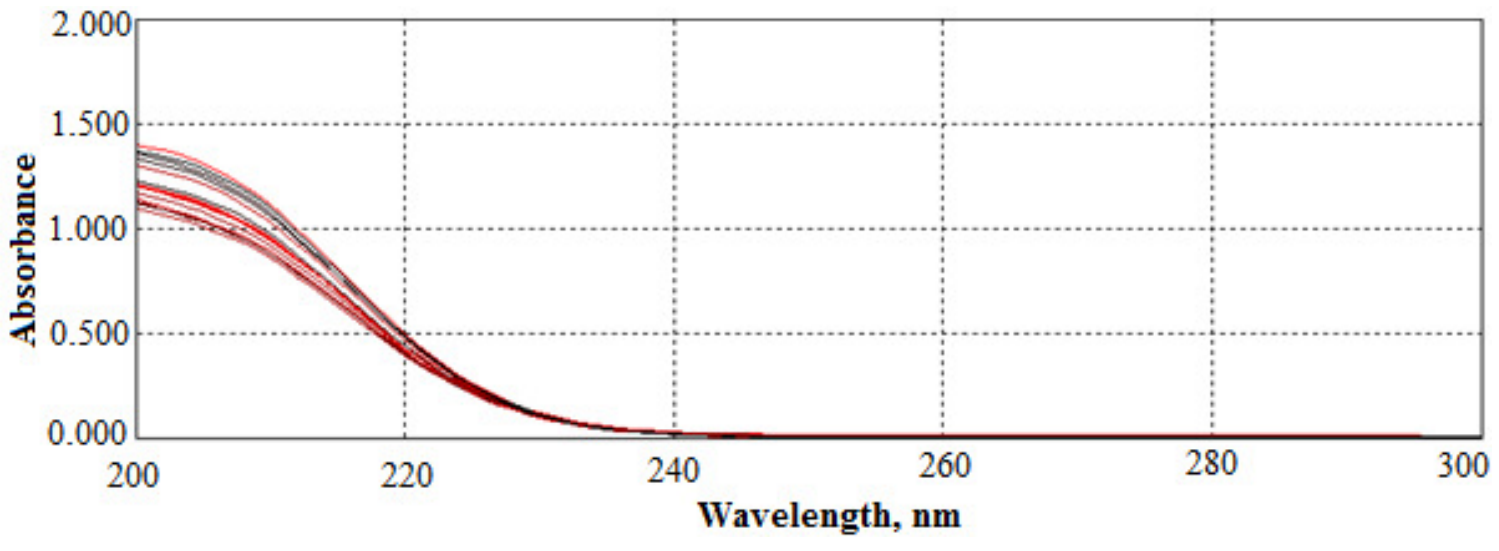

Fig. 2. UV absorption spectra of ozonated water for 30 seconds to 60 minutes

a)

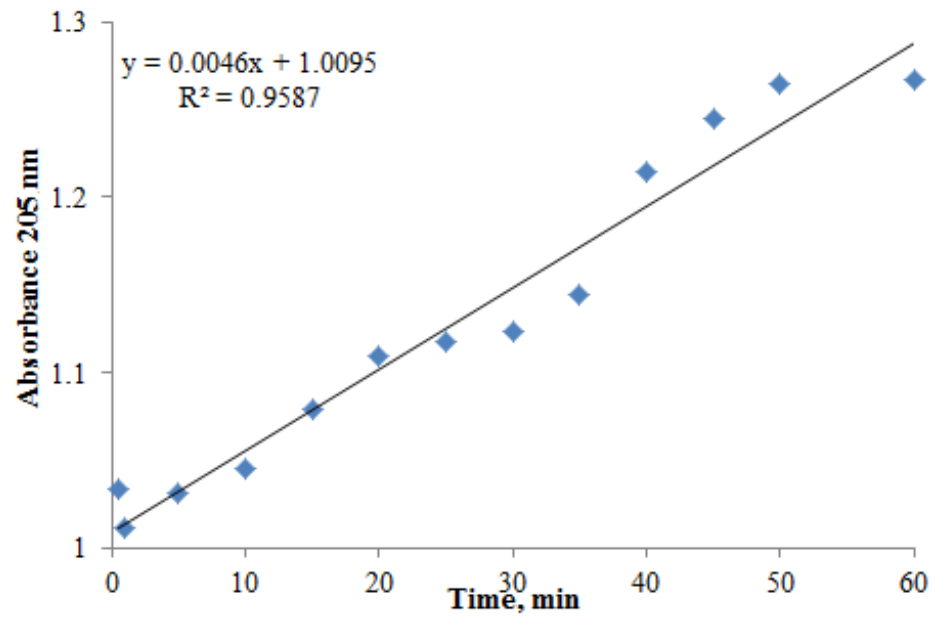

b)

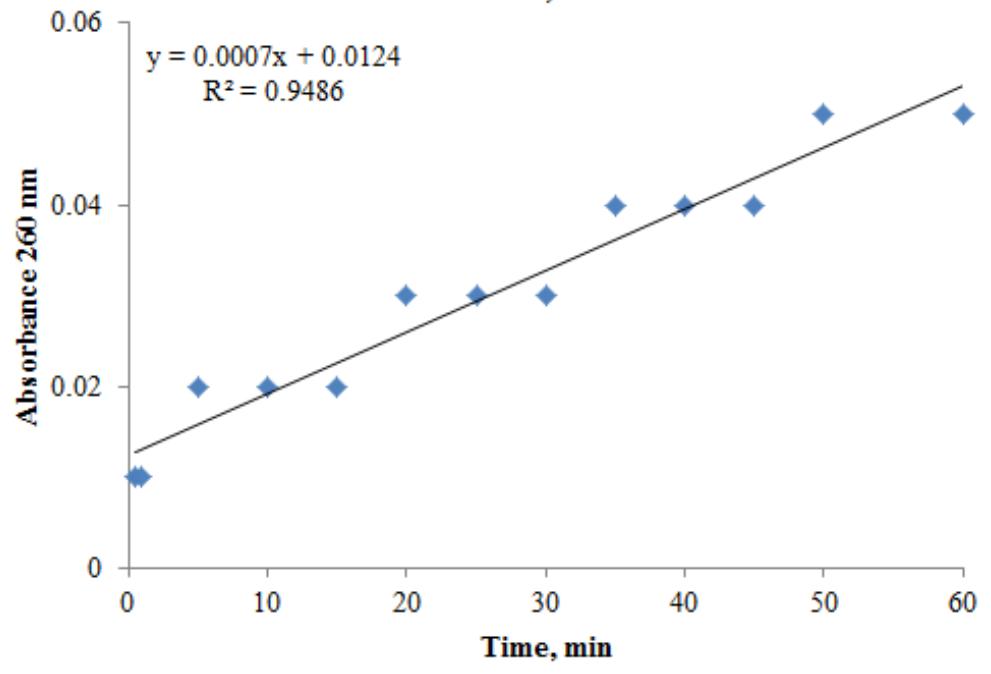

Fig. 3. Variation of absorbance values in water in time for nitrogen oxides (a) and ozone (b) 


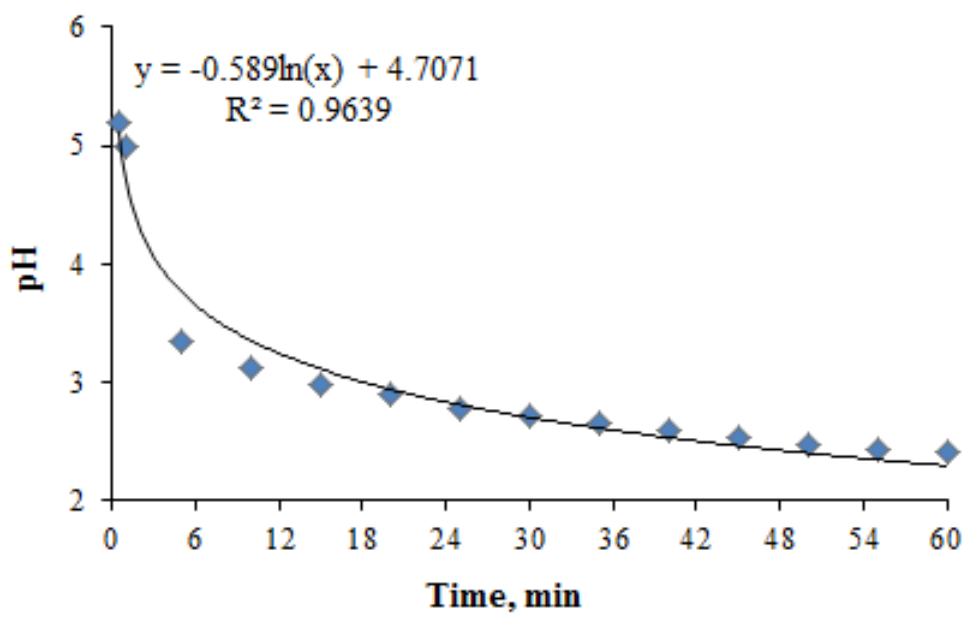

Fig. 4. pH values in ozonated water

Taking into account the fact that the absorption spectra in UV are explained by nitrogen oxide formation, their accumulation in distilled water probably as nitric acid was tested by the recorded $\mathrm{pH}$ values.

After gas bubbling in distilled water, it was found that the $\mathrm{pH}$ decreases drastically from 5.95 units to 2.41 units after 60 minutes. The decrease is very intensive in the first 5 minutes up to a value of 3.3 units, then the decrease is slower, according to Fig. 4. This is explained by the reaction of nitrogen oxides with water and by the formation of nitric acid and other unknown acidic compounds. This low value of $\mathrm{pH}$ was maintained even after a month of storage of the treated water sample. Thus, after 30 minutes since the ozone generator has stopped, the $\mathrm{pH}$ value was 2.4 , the same as the value determined after 60 minutes.

After 3 days, the $\mathrm{pH}$ value increased slightly to 2.6 units, and after a month at a value of 2.7 units. This indicates that the compounds responsible for the $\mathrm{pH}$ decrease are very stable over time.

Taking into account the unexpected results, the experiments have been repeated both for distilled water and for tap water, the results showing the same formation process for nitrogen oxides and ozone species.

\section{Conclusions}

1. Using the titrimetric method, high concentrations of oxidative compounds were found reaching a value of about $1.6 \mathrm{mg} \cdot \mathrm{ml}^{-1}$ expressed as ozone concentration.

2. The ozonated water contained high concentrations of nitric oxides and relatively low concentration of O3, as determined in the UV absorption spectra between 200-300 nm.

3. Determination of $\mathrm{pH}$ values in ozonated water was in correlation with the absorption spectra and suggests the presence of nitric acid and other acidic compounds formed after the treatment.

4. In distilled water samples subjected to ozone treatment,by the methods used, both ozone and nitrogen oxides resulted by oxidation of gaseous compounds from air ( $\mathrm{O} 2$ and $\mathrm{N} 2)$ were determined.

\section{References}

[1] Rodriguez A., Rosal R., Perdigon-Melon J.A., Mezcua M., Aguera A., Hernando M.D., Leton P., Fernandez-AlbaA.R., Garcia-Calvo E.The handbook of environmental chemistry. Berlin Heidelberg: Springer, 2008, $281 \mathrm{p}$.

[2] Ma S., Kim K., Huh J., Eun Kim D., Lee S., Hong Y. Regeneration and purification of watersoluble cutting fluid through ozone treatment using an air dielectric barrier discharge. Separation and Purification Technology, 2018. doi: https://doi.org/10.1016/j.seppur.2018.02.005.

[3] De Almeida Monaco K., Costa S.M., Minatel I.O., Correa C.R., Calero F.A., Vianello F., Lima G.P.P. Influence of ozonated water sanitation on postharvest quality of conventionally and organically cultivated mangoes after postharvest storage. Postharvest Biology and Technology, vol. 120, 2016, pp. 69-75. 
[4] Pekarek S. Non-thermal plasma ozone generation. ActaPolytechnica, vol. 43, 2003, pp. 47-51.

[5] Mennad B., Harrache Z., Amir Aid D., Belasri A.Theoretical investigation of ozone production in negative corona discharge. Current Applied Physics, vol. 10, 2010, pp. 1391-1401.

[6] Smith W. Principles of ozone generation. Watertec Engineering Pty Ltd, Australia. [online][19.03.2018] Available at:

http://watertecengineering.com/TZ000002\%20Principles \%20of \%20Ozone \%20Generation.pdf.

[7] Chen J., Davidson J.H. Ozone production in the positive DC corona discharge: model and comparison to experiments. Plasma Chemistry and Plasma Processing, vol. 22, 2002, pp. 495-522.

[8] Prabakaran M., Tamil Selvi S., Merinal S., Panneerselvam A.Effect of ozonation on pathogenic bacteria. Advances in Applied Science Research, vol. 3, 2012, pp. 299-302.

[9] Oh J.S., Yajima H., Hashida K., Ono T., Ishijima T., Serizawa I., Furuta H., Hatta A. In-situ UV absorption spectroscopy for observing dissolved ozone in water. Journal of Photopolymer Science and Technology, vol. 29, 2016, pp. 427-432.

[10] Masschelein W.J. Measurement of high ozone concentrations in gases by KI titration and monitoring by UV-Absorption. Ozone Science \& Engineering, International Ozone Association, vol. 20, 1998, pp. 489-493. 